\title{
Behaviour of effector cells, synovial fluids, and sera from rheumatoid arthritis patients in antibody-dependent cell-mediated cytotoxicity
}

\author{
L. ANNE COOKE, ${ }^{1}$ F. C. HAY, ${ }^{1}$ AND R. PERUMAL ${ }^{2}$
}

From the ${ }^{1}$ Department of Immunology, Middlesex Hospital Medical School, London, and the ${ }^{2}$ Department Rheumatology, The London Hospital, London

SUMMARY Antibody-dependent cell-mediated cytotoxicity (ADCC) was examined in patients with rheumatoid arthritis (RA). The cytotoxicity of peripheral blood leucocytes from patients with $R \AA$ was similar to that found in normal persons, whereas ADCC was less effective in RA synovial fluig cells. It is possible that the activity in these cells is lower because of immune complexes and othet factors being absorbed from the synovial fluid itself. Although patients' sera had little effect ơ normal peripheral blood leucocytes, synovial fluid from RA patients was markedly inhibitory if ADCC. The degree of inhibition correlated significantly with the clinical status of the patients.

Antibody-dependent cell-mediated cytotoxicity (ADCC) involves the cytolysis of antibody-coated target cells, which are recognised through Fc receptors on the effector cells. Since this phenomenon was first described (Perlmann and Holm, 1969; MacLennan et al., 1970) many workers have undertaken investigations using mammalian erythrocytes or nucleated cells as targets, and implicating as effectors adherent mononuclear cells, nonphagocytic nonadherent Fc-receptor-bearing lymphocytes, and polymorphonuclear leucocytes (MacLennan et al., 1972; Perlmann et al., 1972; Gale and Zighelboim, 1974; MacDonald et al., 1975; Trinchieri et al., 1975; Penfold et al., 1976; Fink et al., 1977).

The importance of ADCC as a mechanism in which extracellular killing of antibody-coated targets may provide a defence against infection and the possible role of ADCC in tumour immunity and allograft rejection have been strongly inferred from in vitro studies. In rheumatoid arthritis (RA) it is conceivable that ADCC may be associated with the formation of rheumatoid pannus tissue and could be a significant factor in the chronicity of the inflammation. Therefore we have compared ADCC of patients' cells to normal cells, and investigated the interaction of RA sera and synovial fluids with normal ADCC.

Accepted for publication 12 June 1978

Correspondence to Dr L. Anne Cooke, Kennedy Institute of Rheumatology, 6 Bute Gardens, London W6 7DW.

\section{Patients and methods}

A total of 57 patients with RA were studied ( female, 13 male). Their average age was $57 \cdot 5$ yeass (range 27 to 81 years), and duration of disease wăb 13.0 years (range 0.5 to 40 years). All patients were classified according to American Rheumatis Association criteria as classical, definite, or prebable. Activity of disease was assessed clinically and designated as active (or very active), moderate active, and inactive. The clinical criteria used wege duration of morning stiffness, synovial swelling ang presence or absence of effusions, and tenderness $\&$ affected joints. Patients who were designated very active or active had morning stiffness of over 3 hours, effusions of 1 or more joints, and a mark synovial swelling and tenderness of the affected joinst: Moderately active patients had morning stiffnes? lasting for more than 1 hour but less thă 3 hours, moderate synovial swelling and minimal tenderness of the affected joints. and no effusiorfs. The inactive category of patients had morning stifirness of less than 1 hour. minimal or no synove swelling, and no tenderness of the affected join 6 .

Synovial fluid samples were obtained by needle aspiration. The synovial fluid cells (SFC) and peripheral blood leucocytes (PBL) were examined in ADCC on the day of collection; cell-free synovi fluids and sera were stored at $-20^{\circ} \mathrm{C}$. PBL and sefa from 13 healthy volunteers working in the imminology laboratory served as controls, and synovigl 
fluids from 4 osteoarthrosis (OA) patients were used as control effusions. Since it was not possible to obtain normal SFC, PBL were compared. In addition, synovial fluids and sera from 22 patients with other connective tissue diseases including ankylosing spondylitis, psoriatic arthritis, systemic lupus erythematosus, Reiter's disease, and Sjögren's syndrome were studied.

\section{ASSAY}

The method of assay was essentially that of Perlmann and Perlmann (1970). A microtitre assay was adapted from Zeijlemaker et al. (1975). Eagle's minimum essential medium (MEM, Flow Laboratories, Irvine, Scotland) was used throughout. For incubations and culture the MEM was supplemented with fetal calf serum (FCS, Flow Laboratories) and heatinactivated at $56^{\circ} \mathrm{C}$ for 30 minutes. The targets were fresh cells taken from the wing vein of a white Leghorn chicken (CRBC) and labelled with 150 $\mu \mathrm{CiNa}_{2}{ }^{51} \mathrm{CrO}_{4}$ (CJS. 1P Radiochemical Centre, Amersham). After incubation for 1 hour with $5 \%$ $\mathrm{CO}_{2}$ and air at $37^{\circ} \mathrm{C}$ in MEM supplemented with $10 \%$ FCS the CRBC were washed 4 times in cold MEM with $5 \%$ FCS, then diluted to a concentration of $1 \times 10^{5}$ cells per ml. $10^{7}$ sheep red blood cells (SRBC) were added to each $\mathrm{ml}$ of CRBC suspension to ensure a consistently low spontaneous release of isotope from the CRBC. Effector cells were obtained from peripheral blood by sedimentation at $37^{\circ} \mathrm{C}$ for 30 minutes, 4 parts blood to 1 part plasmagel being used. The supernatant was diluted with MEM at $37^{\circ} \mathrm{C}$ and washed 4 times. The effector cells from fresh synovial fluids were washed 4 times with MEM at $37^{\circ} \mathrm{C}$ and constituted the whole white cell population. Finally the effectors were resuspended in MEM supplemented with $5 \%$ FCS. Cytocentrifuge preparations of some normal and RA samples were prepared.

Cultures were set up in triplicate in Cooke roundbottomed microtitre plates. $5 \times 10^{3}$ target cells were introduced into the wells in $50 \mu l$ aliquots. Effector cells were added to produce effector-to-target ratios of $5: 1,1: 1$, and $1: 5$. In the experimental wells (EXP) $50 \mu l$ of rabbit anti-CRBC antibody in MEM with $5 \%$ FCS were added to give a final dilution of $\frac{1}{30000}$. In one control (CONT), MEM with $5 \%$ FCS replaced antibody. In addition 2 more controls were included: to estimate the spontaneous release of the CRBC targets were incubated in medium alone, and to ensure that antibody did not lyse the CRBC this was incubated with targets. The maximum ${ }^{51} \mathrm{Cr}$ release (MAX) was estimated by adding 100 $\mu l$ of $3 \%$ Decon to target cells. The total radioactivity was measured by counting labelled target cells alone.
The total volume in the microtitre wells was $150 \mu \mathrm{l}$, and the plates were incubated at $37^{\circ} \mathrm{C}$ for 18 hours in air and $5 \% \mathrm{CO}_{2}$.

After incubation $100 \mu \mathrm{l}$ of supernatant were removed from each well; isotope release was measured in a Wallac gamma counter. The maximum release, experimental release, and control release were expressed as a percentage of the total release, and cytotoxicity was calculated as follows:

$$
\frac{\text { EXP release }- \text { CONT release }}{\text { MAX release }- \text { CONT release }} \quad \times 100
$$

\section{EFFECT OF SERA AND SYNOVIAL}

\section{FLUIDS ON NORMAL ADCC}

Prior to use synovial fluids were treated with hyalase (Fisons UK Eire) at 75 units per $\mathrm{ml}$ synovial fluid to reduce viscosity (Hannestad, 1967). All sera and synovial fluids were heat-inactivated at $56^{\circ} \mathrm{C}$ for 30 minutes. $5 \mu \mathrm{l}$ amounts of serum or synovial fluid were included in the assay and normal PBL used as effectors at a 5:1 effector-to-target ratio.

\section{Results}

PATIENTS' CELLS IN ADCC

No significant difference was seen between PBL from 11 normal individuals and 9 patients with classical RA $(P>0 \cdot 3)$. Three patients were clinically active, 3 moderately active, and 3 inactive (Fig. 1). However, when SFC from 10 patients were assayed in the same way, a significant difference in cytotoxicity was observed $(P<0.005)$ (Fig. 2). Eight patients had classical RA, 1 definite, and 1 possible

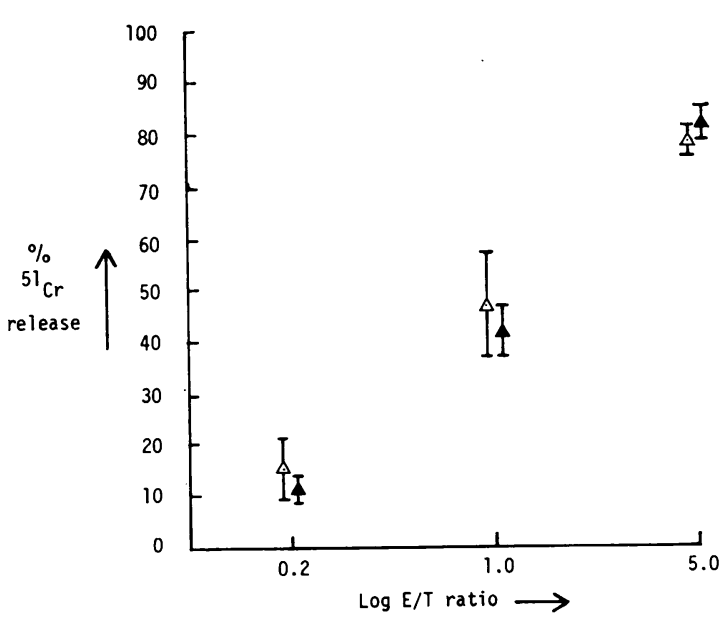

Fig. 1 ADCC of normal $(\Delta)$ and rheumatoid $(\Delta)$ peripheral blood leucocytes at the 1:5, 1:1, and 5:1 effector-to-target cell $(E / T)$ ratio. 


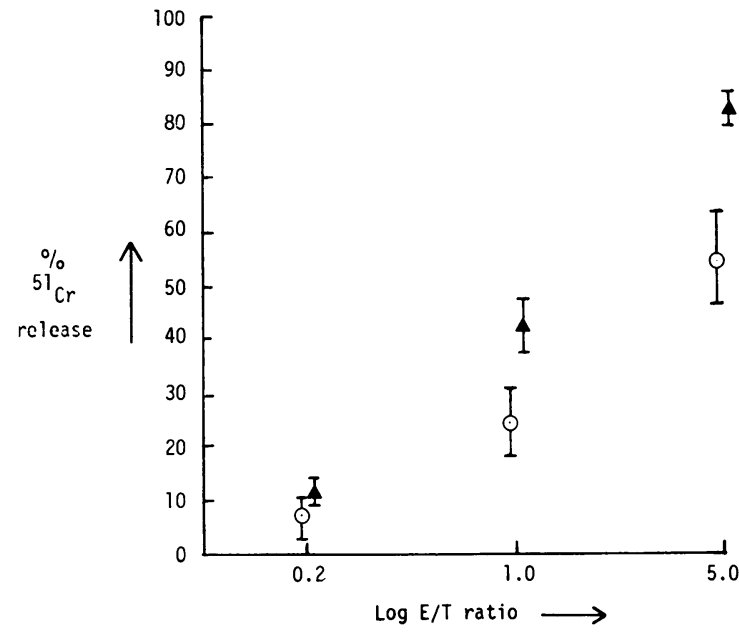

Fig. 2 ADCC of normal peripheral blood leucocytes ( $)$ compared with rheumatoid synovial fluid cells $(o)$.

RA. No difference could be seen between patients with clinically active disease and those with moderately active or inactive RA $(\mathrm{P}>0.95)$.

\section{CYTOCENTRIFUGE PREPARATIONS}

To test whether differences in effector cell activity of RA PBL and SFC were due to variations in the numbers of effector cells cytocentrifuge preparations of representative samples were made. The proportions of each cell population, as distinguished by staining the slides with May-Grünwald-Giesma stain, were similar (Fig. 3).

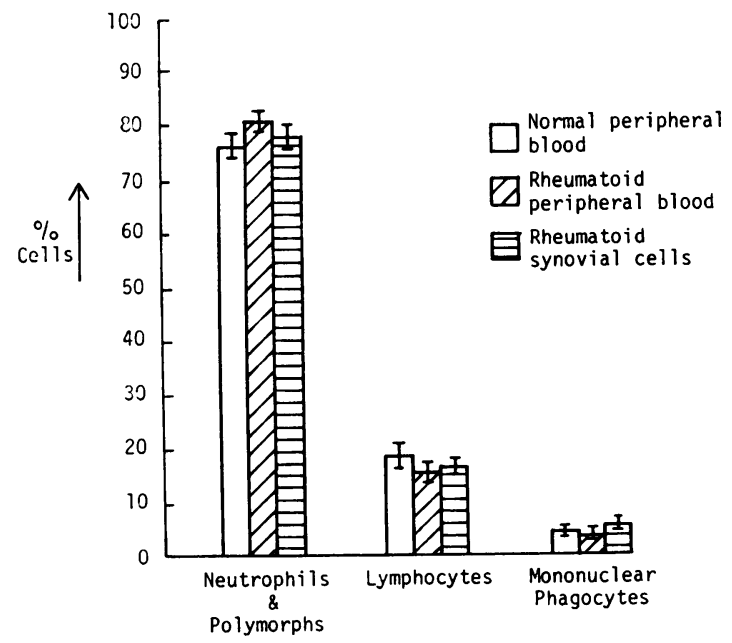

Fig. 3 Cytocentrifuge preparations of normal and rheumatoid samples showing the distribution of cell populations.
EFFECTS OF SERA AND SYNOVIAL FLUIDS IN NORMAL ADCC

When $5 \mu \mathrm{l}$ aliquots of sera were included in the assay using normal PBL effectors, no significant difference was observed between 8 normal human sera (NHS) and 17 sera from RA patients $(\mathrm{P}<0 \cdot 1)$. There was significant difference $(P<0.025)$ between NHS and 8 sera from patients with other connective tissues diseases (Fig. 4). However, in relation to NHS there was a significant inhibition of cytotoxicity on addition of $5 \mu$ l samples of synovial fluid from RAw patients $(\mathrm{P}<0 \cdot 005)$ and patients with other inflam matory connective tissue disorders $(\mathrm{P}<0 \cdot 001)$ (Fig? 4). Compared to NHS, fluids from patients with $O A_{\infty}^{\omega}$ were also significantly inhibitory $(P<0.02)$ but lessi so than the other fluids tested. This might be \& reflection of the difficulty in selecting patients with degenerative joint disease with no other concurrene disease. Since normal synovial fluid is not available for ethical and other reasons, it was not possible tof determine whether there were factors in synovia fluid which are naturally inhibitory in ADCC.

30 RA synovial fluids were examined; 23 patientso had classical RA, 2 definite RA, and 5 probablep Synovial fluids from RA patients with active disease showed significantly more inhibition than those from patients with moderately active and inactive disease $(P<0.005)$ (Fig. 5). This was not so when patients' SFC were examined.

However, there was no difference in inhibitory? capacity of synovial fluids of RA patients with or without radiological erosions, or positive and nega tive serology. Similarly, the drug regimen did no seem to influence the degree of inhibition of cyto toxicity by the synovial fluids. Anti-inflammatory
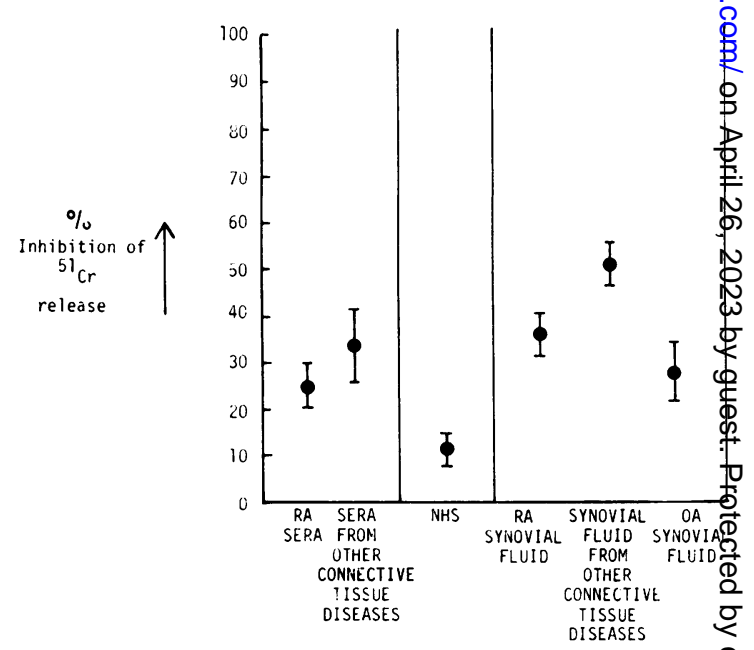

Fig. 4 Inhibition of $A D C C$ by sera and synovial fluids. 


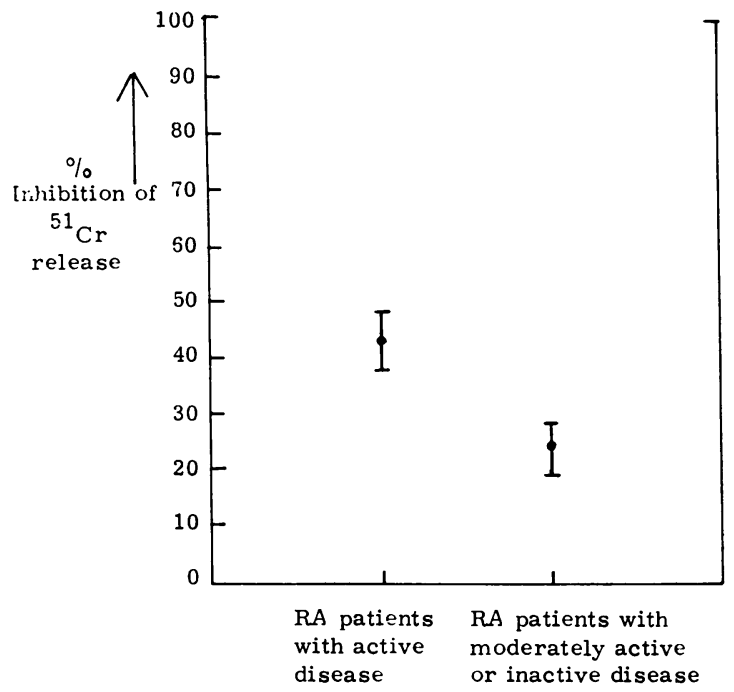

Fig. 5 The relationship between rheumatoid disease activity and inhibition of normal ADCC by synovial fluids.

drugs, immunosuppressive drugs, and steroid therapy, whether taken singly or in combination, did not affect the inhibitory capacity of the synovial fluids.

\section{Discussion}

Several different effector cell types have been implicated in ADCC, and it would appear that the choice of target cell could be a determining factor. Since at this stage we are not sure which cells might play an active role in RA, it was decided to combine all effector populations and include whole white cell populations when comparing normal individuals and patients with RA.

This study showed that RA SFC were significantly less cytotoxic than with normal PBL. Diaz-Jouanen et al. (1976a) reported a decrease in cytotoxicity with RA SFC (using polymorphs or lymphocytes as effectors) compared with peripheral blood lymphocytes from RA patients and normal controls. Cytotoxicity was assessed by isotope released from sensitised CRBC targets. Conversely, using burro erythrocyte targets, Scheinberg and Cathcart (1976) found that purified rheumatoid peripheral blood lymphocytes and SFC mediated ADCC normally, and that no correlation could be obtained between the percentages of $\mathrm{T}, \mathrm{B}$, and null cells in the effector populations and the amount of cytotoxicity.

In their experiments on the inhibition of cytotoxicity using RA sera and synovial fluids DiazJouanen et al. (1976b) found that most sera and synovial fluids were inhibitory, whereas Scheinberg and Cathcart (1976) showed that sera from 50\% of their patients with RA inhibited ADCC by normal lymphocytes. Our studies have shown clearly that RA synovial fluids show more inhibition of ADCC than NHS, and it seems most likely that this can be attributed to the higher concentration of $\mathrm{Clq}$ binding complexes in RA joint effusions in relation to serum (Hay et al., 1978), and, further, that ADCC activity is lower in RA SFC as a result of blocking of their Fc receptors by these complexes. It is not surprising, therefore that the cytotoxicity of normal and RA PBL is similar in view of the comparable effects of NHS and RA sera on normal effector cells. However, we were unable to produce further evidence of immune complex involvement in reduced cytotoxicity using the methods described by Feldman et al., (1976), who demonstrated a partial regeneration of ADCC by treatment of peripheral blood lymphocytes of SLE patients with Pronase and DNase, followed by incubation overnight (Cooke, unpublished data).

The greatest inhibition of normal cells was by synovial fluids from patients with the most active disease. On this basis, we would expect there to be a similar relationship between disease activity and reduced cytotoxicity of SFC, but insufficient numbers were studied to establish this point.

We thank Professor I. M. Roitt for suggestions and advice, and the medical staff of the Rheumatology Department for providing some patients' specimens.

This reseach was funded by the Medical Research Council.

\section{References}

Diaz-Jouanen, E., Bankhurst, A. D., and Williams, Jr. R. C. (1976a). Antibody-mediated lymphocytotoxicity in rheumatoid arthritis and systemic lypus erythematosus. Arthritis and Rheumatism, 19, 133-141.

Diaz-Jouanen, E., Bankhurst, A. D., Messner, R. P., and Williams, Jr. R. C. (1976b). Serum and synovial fluid inhibitors of antibody-mediated lymphocytotoxicity in rheumatoid arthritis and systemic lupus erythematosus. Arthritis and Rheumatism, 19, 142-149.

Feldman, J., Becker, M. J., Moutsopoulos, H., Fye, K., Blackman, M., Epstein, W. V., and Talal, N. (1976). Antibody-dependent cell-mediated cytotoxicity in selected autoimmune diseases. Journal of Clinical Investigation, 58, 173-179.

Fink, P. C., Schedel, I., Peter, H. M., and Deicher, M. (1977). Inhibition of spontaneous and antibody-dependent cellular cytotoxicity by sera and isolated antiglobulin preparations from rheumatoid arthritis patients. Scandinavian Journal of Immunology, 6, 173-183.

Gale, R. P., and Zighelboim, J. (1974). Modulation of polymorphonuclear leukocyte-mediated antibodydependent cellular cytotoxicity. Journal of Immunology, 113, 1793-1800.

Hannestad, K. (1967). Presence of aggregated y-globulin in certain rheumatoid synovial effusions. Clinical and experimental Immunology, 2, 511-529. 


\section{Cooke, Hay, Perumal}

Hay, F. C., Nineham, L. J., Perumal, R., and Roitt, I. M. Intra-articular and circulating immune complexes and and antiglobulins (IgG and IgM) in rheumatoid arthritis: correlation with clinical features. Annals of the Rheumatic Diseases, 1979, 38, 1-7.

MacDonald, H. R., Bonnard, G. D., Sordat, B., and Zawodnik, S. A. (1975). Antibody-dependent cell-mediated cytotoxicity: heterogeneity of effector cells in human peripheral blood. Scandinavian Journal of Immunology, 4, 487-497.

MacLennan, I. C. M. (1972). Antibody in the induction and inhibition of lymphocyte cytotoxicity. Transplantation Reviews, 13, 67-90.

MacLennan, I. C. M., Loewi, G., and Harding, B. (1970). The role of immunoglobulins in lymphocyte-mediated cell damage in vitro. Immonulogy, 18, 397-404.

Penfold, P. L., Greenberg, A. H., and Roitt, I. M. (1976) Characteristics of the effector cells mediating cytotoxicity against antibody-coated target cells. Clinical and Experimental Immunology, 23, 91-97.
Perlmann, P., and Holm, G. (1969). Cytotoxic effects lymphoid cells in vitro. Advances in Immunology, 11 117-193.

Perlmann, P. ,and Perlmann, H. (1970). Contractual lysis of antibody-coated chicken erythrocytes by purifieg lymphocytes. Cellular Immunology, 1, 300-315.

Perlmann, P., Perlmann, H., and Wigzell, H. (1972कू Lymphocyte mediated cytotoxicity in vitro. Induction an inhibition by humoral antibody and nature of effector cells? Transplantation Reviews, 13, 91-114.

Scheinberg, M. A., and Cathcart, E. S. (1976). Antibodydependent direct cytotoxicity of human lymphocyte? Clinical and Experimental Immunology, 24, 323-327.

Trinchieri, G., Bauman, P., De Marchi, M., and Tökes, Ż (1975). Antibody-dependent cell-mediated cytotoxicity ion humans. Journal of Immunology, 115, 249-255.

Zeijlemaker, W. P., Roos, M. Th. L., Schellekens, P. Th. A and Eijsvoogel, V. P. (1975). Antibody-dependent humạo lymphocytotoxicity: a micro-assay system. Europedin Journal of Immunology, 5, 579-584. 